\title{
Efficacy of transepithelial corneal collagen crosslinking for keratoconus: I 2-month follow-up
}

\author{
This article was published in the following Dove Press journal: \\ Clinical Ophthalmology \\ 21 April 2017 \\ Number of times this article has been viewed
}

\author{
Mohamed A Heikal \\ Tarek Tawfik Soliman \\ Ayser Fayed \\ Abdelmonem M Hamed \\ Department of Ophthalmology, \\ Benha University, Benha, Egypt
}

Correspondence: Mohamed A Heikal Department of Ophthalmology, Benha University, 17 Fareed Nada Street, Benha 135II, Egypt

Tel +20 0100 7I3 I43I

Email mohammedheikel@gmail.com
Purpose: To evaluate the efficacy of transepithelial corneal collagen crosslinking (TE-CXL) in patients with progressive keratoconus.

Patients and methods: This is a prospective interventional consecutive study carried out on 30 eyes of 18 patients with progressive keratoconus who underwent TE-CLX using both ParaCel ${ }^{\mathrm{TM}}$ (riboflavin $0.25 \%$, hydroxy propyl methyl cellulose, $\mathrm{NaCl}$, ethylenediaminetetraacetic acid [EDTA], Tris, and benzalkonium chloride) and vibeX-Xtra (riboflavin $0.22 \%$, phosphatebuffered saline solution). The procedure was carried out at Ebsar Eye Center in Egypt in the period from 2012 to 2014 . The follow-up visits were scheduled on days 1, 3, 6, and 12 months after treatment.

Results: There were statistically significant improvements $(P<0.001)$ in the mean best-corrected visual acuity $(0.54 \pm 0.22$ preoperatively vs $0.61 \pm 0.19$ at 12 months postoperatively), the mean manifest refraction spherical equivalent (MRSE; $-6.16 \pm 3.90$ diopters [D] preoperatively and $-5.91 \pm 3.72 \mathrm{D}$ at 12 months postoperatively), and the mean preoperative corneal astigmatism $(-3.39 \pm 2.11 \mathrm{D}$ preoperatively and $-2.46 \pm 2.60 \mathrm{D}$ at 12 months postoperatively).

Conclusion: TE-CXL could halt the progression of keratoconus in adult patients. TE-CXL resulted in a statistically significant improvement in best-corrected visual acuity, manifest refraction, refractive and corneal astigmatism and $\mathrm{K}$ values in keratoconus patients at the 12-month follow-up. Larger sample sizes and longer follow-ups are required in order to make meaningful conclusions.

Keywords: corneal astigmatism, refractive astigmatism, transepithelial crosslinking, progressive keratoconus

\section{Introduction}

Keratoconus is the most common cause of primary keratectasia, which usually occurs bilaterally during puberty and progresses until the mid-age. ${ }^{1,2}$

Conventional treatment for keratoconus includes rigid contact lens, intracorneal ring segments, and penetrating keratoplasty. In recent years, the objectives of treatment were not only improvement of visual acuity but also preventing disease progression. ${ }^{3}$

Corneal collagen crosslinking (CXL) aided by photosensitized riboflavin helps stabilize progressive keratoconus and may delay the need for keratoplasty. ${ }^{4}$

CXL is the only treatment option that focused on disease pathology and increasing the biomechanical rigidity of the cornea.,

Epithelial debridement was conventionally done before exposing the corneal stroma to ultraviolet-A (UVA), which enhances the stromal penetration of photoactivated riboflavin. Debriding the corneal epithelium increases the risk of infection, sub-epithelial haze, sterile corneal infiltrates, corneal scarring, and endothelial damage. ${ }^{1,7-10}$ 
Transepithelial (TE) technique has been introduced to combine the advantages of the conventional technique in addition to maintaining a higher safety profile. ${ }^{11,12}$

Our aim in this study is to evaluate the efficacy of TECLX in the treatment of keratoconus patients after 12-month follow-up.

\section{Patients and methods}

This is a prospective interventional consecutive study carried out on 30 eyes of 18 patients with progressive keratoconus who underwent TE-CLX. The procedure was carried out at Ebsar eye center in Egypt in the period from 2012 to 2014.

Inclusion criteria: patients with progressive keratoconus who have changes of $\geq 1.00$ diopters (D) in the steepest keratometry (K) measurement over 12 months, keratometry between 47 and $55 \mathrm{D}$, and corneal thinnest point (CTP) $>400 \mu \mathrm{m}$.

Exclusion criteria: previous history of corneal surgery or chemical injury and patients with CTP $<400 \mu \mathrm{m}$.

All the patients had preoperative evaluation including manifest best-corrected visual acuity (BCVA; decimal), spherical equivalent, slit-lamp biomicroscopy, CTP, and corneal topographic analysis ( $\mathrm{K} \max$ and $\mathrm{K}$ astigmatism) using Scheimpflug corneal tomography (OCULUS Pentacam ${ }^{\circledR}$; OCULUS Inc., Berlin, Germany).

Preoperative written informed consent was obtained from the patients. Written informed consent to publish the data of this paper was also obtained from the patients. This research has been approved by the Ebsar Eye Center Institutional Review Board.

\section{The procedure}

The procedure was carried out under strict aseptic conditions, through intact corneal epithelium. Benoxinate $(0.04 \%)$ anesthetic drops were instilled twice, every 5 minutes. Sufficient amount of ParaCel ${ }^{\mathrm{TM}}$ (riboflavin $0.25 \%$, hydroxy propyl methyl cellulose [HPMC], $\mathrm{NaCl}$, ethylenediaminetetraacetic acid [EDTA], Tris, and benzalkonium chloride [BAC]) was applied to completely cover the cornea.

This procedure was repeated every 90 seconds for a total of 4 minutes. The cornea was then rinsed with vibeX-Xtra (riboflavin $0.22 \%$, phosphate-buffered saline solution).

Sufficient vibeX-Xtra was applied to completely cover the cornea. This procedure was repeated every 90 seconds for a total of 5 minutes. Slit-lamp verification of the stromal saturation was done before the UVA radiation.

The UV treatment was then initiated using Xlink system (OptoXLink, Opto Global Pty Ltd, Adelaide, Australia) at $3 \mathrm{~mW} / \mathrm{cm}^{2}$ for 30 minutes. The size of the treatment beam should be the largest possible but smaller than limbus diameter to avoid destruction of corneal stem cells.

Under the UV treatment, vibeX-Xtra was applied every 5 minutes during irradiation until the end of the procedure. The cornea then rinsed with balanced salt solution (BSS).

\section{Postoperative care}

Antibiotic eye drops (tobramycin $0.3 \%$ ) and topical steroids eye drops (fluorometholone $0.1 \%$ ) were given 5 times daily for 2 weeks with tapering of corticosteroid eye drops over another 2 weeks. Artificial eye drops were given for 3 months.

Follow-up of the patient was scheduled for day 1 and day 7 postoperatively and subsequently at 3, 6, and 12 months postoperatively.

BCVA, spherical equivalent, corneal topography, and CTP were documented at each follow-up visit.

\section{Statistical analysis}

Statistical analysis was performed to compare the postoperative data with the preoperative data using the paired $t$-test with IBM Statistical Package for the Social Sciences (SPSS) Statistics v19.0 (IBM, Armonk, NY, USA). $P<0.05$ was considered statistically significant.

\section{Results}

Thirty eyes of 18 patients with a mean age of $25.2 \pm 6.19$ years, ranged (17-38 years), were enrolled in this prospective clinical study. The 30 eyes with progressive keratoconus had TE-CXL treatment and were followed-up for 12 months.

\section{Functional results after TE-CXL}

The preoperative mean BCVA was $0.54 \pm 0.227$. At 3 months postoperatively the mean BCVA was $0.54 \pm 0.21$, at 6 months postoperatively the mean BCVA was $0.60 \pm 0.20$, and was $0.61 \pm 0.19$ at 12 months postoperatively (Figure 1).

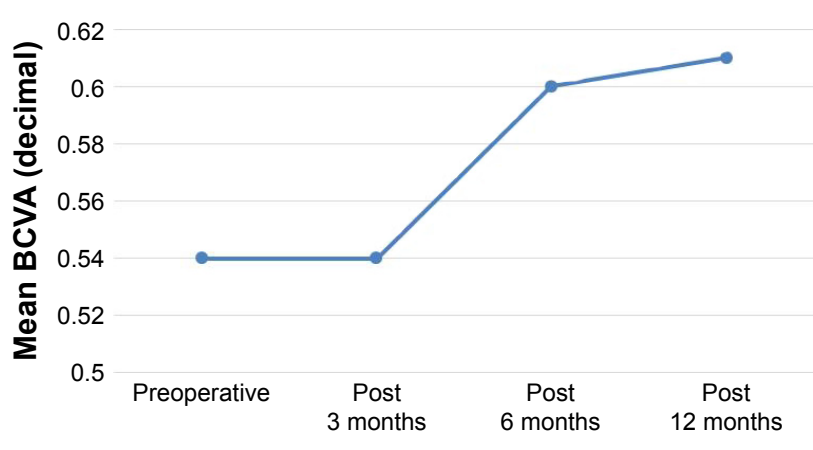

Figure I Mean best-corrected visual acuity (BCVA) in decimal pre- and posttransepithelial corneal crosslinking in keratoconus patients. 
The mean BCVA improved significantly at 3,6, and 12 months postoperatively $(P<0.05)$. At 12 months postoperatively, the mean BCVA improved by one or more Snellen lines in $63.33 \%$ (19 eyes), remained stable in $26.66 \%$ (8 eyes), and 3 eyes (10\%) lost 1 Snellen line.

\section{Refractive changes after TE-CXL}

The preoperative mean manifest refraction spherical equivalent (MRSE) was $-6.16 \pm 3.90$. At 3 months postoperatively, it was $-5.85 \pm 3.82$. At 6 months postoperatively, it was $-5.69 \pm 3.78$. At 12 months postoperatively, it was $-5.91 \pm 3.72$ (Figure 2).

There was statistically significant improvement in the mean MRSE at 3, 6, and 12 months postoperatively $(P<0.05)$.

Preoperatively, the mean refractive astigmatism was $-3.01 \pm 2.64$. At 3 months postoperatively, it was $-2.83 \pm$ 2.72. At 6 months postoperatively, it was $-2.27 \pm 2.35$. At 12 months postoperatively, it was $-2.46 \pm 2.60$ (Figure 3).

The mean preoperative refractive astigmatism was statistically significant difference from postoperative visit $(P<0.05)$.

The mean refractive astigmatism improved by $-1.00 \mathrm{D}$ or more in 5 eyes $(16.66 \%)$, changed between $-0.5 \mathrm{D}$ and $-1 \mathrm{D}$ in 19 eyes $(63.33 \%)$ and remained stable in 6 eyes $(20 \%)$.

\section{Topography changes after TE-CXL}

The preoperative mean $\mathrm{K}$ maximum was $49.81 \pm 3.79$. At 3 months postoperatively, it was $49.22 \pm 3.65$. At 6 months postoperatively, it was $48.74 \pm 3.81$. At 12 months postoperatively, it was $48.86 \pm 3.94$.

There was a significant decrease in the mean $\mathrm{K}$ maximum value between preoperative and 12 months postoperative follow-up $(P<0.05)$. There was also a significant decrease in the mean $\mathrm{K}$ maximum at 3 and 6 months, respectively $(P<0.05)$.

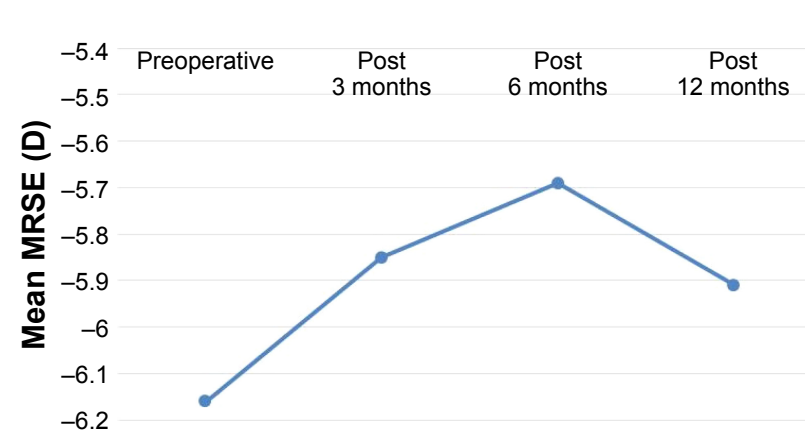

Figure 2 Mean MRSE in diopter (D) pre- and posttransepithelial corneal crosslinking in keratoconus patients.

Abbreviation: MRSE, manifest refraction spherical equivalent.

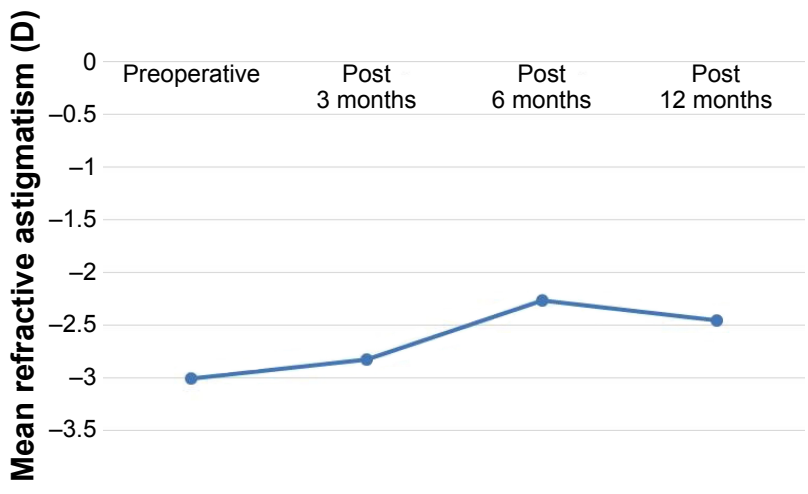

Figure 3 Mean refractive astigmatism in diopter (D) pre- and posttransepithelial corneal crosslinking in keratoconus patients.

The mean $\mathrm{K}$ maximum value decreased by $1 \mathrm{D}$ or more in 23 eyes (76.66\%), remained unchanged in 4 eyes (13.33\%) and increased by $1 \mathrm{D}$ in 3 eyes $(10 \%)$.

The preoperative mean $\mathrm{K}$ was $46.42 \pm 3.08$. At 3 months postoperatively, it was $45.92 \pm 3.02$. At 6 months postoperatively, it was $45.9 \pm 3.09$. At 12 months postoperatively, it was $45.68 \pm 3.19$.

There was a significant decrease in the mean $\mathrm{K}$ value at 12 months postoperatively $(P<0.05)$. The mean $\mathrm{K}$ value decreased by $1 \mathrm{D}$ in 19 eyes $(63.33 \%)$ and remained unchanged in 7 eyes $(23.33 \%)$ and it increased by $1 \mathrm{D}$ in 4 eyes (13.33\%).

The preoperative mean corneal astigmatism was $3.39 \pm 2.11$. At 3 months postoperatively, it was $3.25 \pm 2.18$. At 6 months postoperatively, it was $2.80 \pm 1.67$. At 12 months postoperatively, it was $3.003 \pm 1.93$.

Changes in the mean corneal astigmatism at 3 months postoperatively were statistically insignificant $(P>0.05)$. However, the changes in the mean corneal astigmatism at 6 and 12 months postoperatively were statistically significant $(P<0.05$; Figure 4).

The preoperative mean corneal thickness at thinnest local was $473.16 \pm 43.69$. At 1 month postoperatively, it

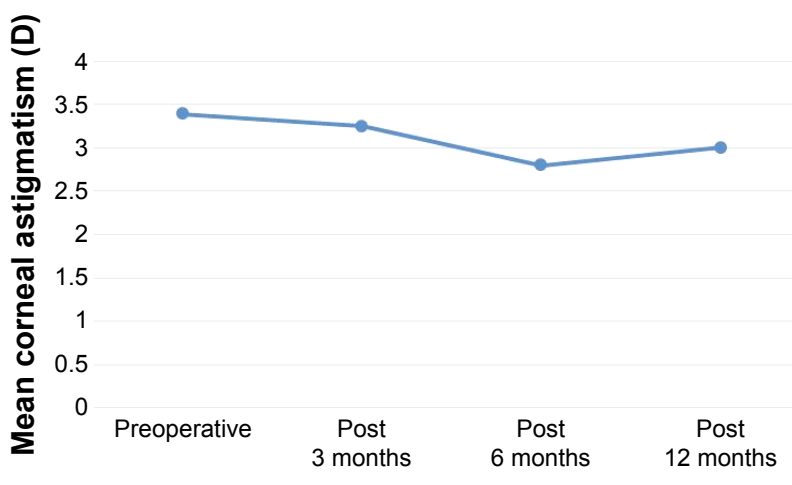

Figure 4 Mean corneal astigmatism in diopter (D) pre- and posttransepithelial corneal crosslinking in keratoconus patients. 
was 443.06 \pm 45.24 . At 3 months postoperatively, it was 458.24 \pm 46.83 . At 12 months postoperatively, it was $457.67 \pm 40.10$.

The mean CTP at 3, 6, and 12 months postoperatively was statistically significant changed $(P<0.05)$. After TE-CXL, CTP thins and then recovered toward the preoperative thickness.

\section{Discussion}

CXL is one of the most recent treatments that halts the progression of keratoconus. It strengthens the cornea by covalently crosslinking the collagen fibers and increases rigidity by $300 \% .^{13}$

The epithelial-off procedure is effective in increasing corneal stiffness, ${ }^{6}$ stabilization of keratoconus, and in some cases in improving the refractive and topographic features, ${ }^{14,15}$ but may lead to serious complications, such as infection, ${ }^{16,17}$ stromal haze, ${ }^{18}$ and corneal melting. ${ }^{19}$

Epithelium-on or TE-CXL, which keeps the epithelial intact, has been introduced by Boxer et al. ${ }^{20}$

Several approaches have been introduced to improve the efficacy of penetration of riboflavin through the epithelium, which is impermeable to riboflavin because of its high molecular weight $(>100 \mathrm{Da}) .^{21}$

The replacement of the isotonic by hypotonic riboflavin solution has been introduced to increase the penetration of riboflavin through the intact epithelium. ${ }^{22}$ Other approaches such as BAC, ${ }^{23}$ trometamol, EDTA, ${ }^{24}$ tetracaine, ${ }^{25}$ ethanol, ${ }^{26}$ partial grid-like pattern de-epithelialization, ${ }^{26}$ and excimer laser superficial epithelial removal ${ }^{27}$ were applied.

This is a prospective interventional consecutive study carried out on 30 eyes of 18 patients with a mean age of $25.2 \pm 6.19$ years, ranged from 17 to 38 years.

The included eyes had progressive keratoconus and underwent TE-CXL treatment using combination of ParaCelTM $^{\mathrm{TM}}$ (riboflavin 0.25\%, HPMC, NaCl, EDTA, Tris, and BAC) and vibeX-Xtra (riboflavin $0.22 \%$, phosphate-buffered saline solution). Follow-up at 12 months postoperatively was recorded.

There was a significant improvement of more than one line of mean BCVA at 12 months postoperatively.

Nineteen eyes (63.33\%) gained one or more Snellen lines of BCVA, 8 eyes remained stable (26.66\%), and only 3 eyes (10\%) lost 1 line of BCVA postoperatively.

Caporossi et $\mathrm{al}^{28}$ reported no statistically significant increase in uncorrected distance visual acuity (UDVA) and BCVA in the first 3 months in cases of keratoconus that were treated with TE-CXL, while Stojanovic et al ${ }^{11}$ reported no cases with a loss of $\geq 2$ lines of BCVA.
Koppen et $\mathrm{al}^{29}$ reported a statistically significant improvement in BCVA at 6 and 12 months in the TE-CLX group. Bernardo et $\mathrm{al}^{30}$ showed significant increase in BCVA in 36 eyes with progressive keratoconus that were treated with TE-CLX after 6 months of follow-up.

In our study, there was a statistically significant improvement in the MRSE at 12 months postoperatively.

In our study, the mean refractive astigmatism improved by $1.00 \mathrm{D}$ or more in 5 eyes $(16.66 \%)$, changed between -0.5 and -1 D in 19 eyes $(63.33 \%)$, and remained stable in 6 eyes $(20 \%)$.

Our result is similar to the study by Koppen et $\mathrm{al}^{29}$ that recorded significant improvement in the mean refractive astigmatism in the TE-CLX group.

The mean $\mathrm{K}$ maximum value decreased by $1 \mathrm{D}$ or more in 23 eyes $(76.66 \%)$, remained unchanged in 4 eyes $(13.33 \%)$, and increased by $1 \mathrm{D}$ in 3 eyes $(10 \%)$.

Stojanovic et $\mathrm{a}^{11}$ reported significant decrease in the $\mathrm{K}$ maximum without changes in the mean $\mathrm{K}$, while Soeters et $\mathrm{al}^{31}$ reported increase of $\mathrm{K}$ maximum more than $1 \mathrm{D}$ after 1 year (range $1.3-5.4 \mathrm{D}$ ) in $23 \%$ of TE group.

Changes in the CTP at 3, 6, and 12 months postoperatively were statistically significant reduced, but they recovered toward the preoperative values in our study $(P<0.05)$.

Bernardo et $\mathrm{al}^{30}$ did not report statistically significant changes in the mean corneal thickness at the thinnest point, while another study reported statistically significant reduction of corneal thickness at the thinnest point. ${ }^{32}$

Previous studies evaluated the anterior chamber depth and anterior chamber value in cases of keratoconus that were treated with CXL. They reported no statistically significant changes in the postoperative value as compared preoperatively. ${ }^{30,32}$

There were no complications recorded in our study. Analysis of the results of our study showed that TE-CLX could halt the progression of keratoconus in adult patients.

The main drawbacks of our study are lack of control group and the need of longer follow-up of patients.

\section{Conclusion}

TE-CXL could halt the progression of keratoconus in adult patients. TE-CXL resulted in a statistically significant improvement in BCVA, manifest refraction, refractive and corneal astigmatism, and $\mathrm{K}$ values in keratoconus patients at the 12-month follow-up. Larger sample sizes and longer follow-ups are required to make meaningful conclusions.

\section{Acknowledgment}

This work was self-funded by the authors. 


\section{Disclosure}

The study was performed at Ebsar Eye Centre, Benha, Egypt. This study was presented as a poster in European Society of Cataract \& Refractive Surgery (ESCRS) 2015. The authors report no conflicts of interest in this work.

\section{References}

1. Kennedy RH, Bourne WM, Dyer JA. A 48-year clinical and epidemiologic study of keratoconus. Am J Ophthalmol. 1986;101(3):267-273.

2. Abbey AM, Yoo SH. Anatomy, physiology, and molecular biology. In: Wang M, Swartz TS, editors. Keratoconus and Keratoectasia: Prevention, Diagnosis, and Treatment. Thorofare, NJ: SLACK; 2010: 3-12.

3. Jhanji V, Sharma N, Vajpayee RB. Management of keratoconus: current scenario. Br J Ophthalmol. 2011;95(8):1044-1050.

4. Hovakimyan M, Guthoff RF, Stachs O. Collagen cross-linking: current status and future directions. J Ophthalmol. 2012;2012:406850.

5. Wollensak G. Crosslinking treatment of progressive keratoconus: new hope. Curr Opin Ophthalmol. 2006;17(4):356-360.

6. Wollensak G, Spoerl E, Seiler T. Riboflavin/ultraviolet-a induced collagen crosslinking for the treatment of keratoconus. Am J Ophthalmol. 2003;135(5):620-627.

7. Spoerl E, Hoyer A, Pillunat LE, Raiskup F. Corneal cross-linking and safety issues. Open Ophthalmol J. 2011;5:14-16.

8. Dhawan S, Rao K, Natrajan S. Complications of corneal collagen crosslinking. J Ophthalmol. 2011;2011:869015.

9. Kymionis GD, Portaliou DM, Bouzoukis DI, et al. Herpetic keratitis with iritis after corneal crosslinking with riboflavin and ultraviolet A for keratoconus. J Cataract Refract Surg. 2007;33(11):1982-1984.

10. Wollensak G, Iomdina E. Biomechanical and histological changes after corneal crosslinking with and without epithelial debridement. J Cataract Refract Surg. 2009;35(3):540-546.

11. Stojanovic A, Chen X, Jin N, et al. Safety and efficacy of epithelium-on corneal collagen cross-linking using a multifactorial approach to achieve proper stromal riboflavin saturation. J Ophthalmol. 2012; 2012:498435.

12. Suri K, Hammersmith KM, Nagra PK. Corneal collagen cross-linking: Ectasia and beyond. Curr Opin Ophthalmol. 2012;23(4):280-287.

13. Spörl E, Huhle M, Kasper M, Seiler T. Artificial stiffening of the cornea by induction of intrastromal cross-links. Der Ophthalmologe. 1997; 94(12):902-906. German.

14. Caporossi A, Baiocchi S, Mazzotta C, Traversi C, Caporossi T. Parasurgical therapy for keratoconus by riboflavin-ultraviolet type A rays induced cross-linking of corneal collagen: preliminary refractive results in an Italian study. J Cataract Refract Surg. 2006;32(5):837-845.

15. Grewal DS, Brar GS, Jain R, Sood V, Singla M, Grewal SPS. Corneal collagen crosslinking using riboflavin and ultraviolet-A light for keratoconus: one-year analysis using Scheimpflug imaging. J Cataract Refract Surg. 2009;35(3):425-432.

16. Zamora KV, Males JJ. Polymicrobial keratitis after a collagen crosslinking procedure with postoperative use of a contact lens: a case report. Cornea. 2009;28(4):474-476.
17. Pérez-Santonja JJ, Artola A, Javaloy J, Alió JL, Abad JL. Microbial keratitis after corneal collagen crosslinking. $J$ Cataract Refract Surg. 2009;35(6):1138-1140.

18. Mazzotta C, Balestrazzi A, Baiocchi S, Traversi C, Caporossi A. Stromal haze after combined riboflavin-UVA corneal collagen cross-linking in keratoconus: in vivo confocal microscopic evaluation. Clin Exp Ophthalmol. 2007;35(6):580-582.

19. Eberwein P, Auw-Hädrich C, Birnbaum F, Maier PC, Reinhard T. Corneal melting after cross-linking and deep lamellar keratoplasty in a keratokonus patient. Klin Monbl Augenheilkd. 2008;225(1):96-98. German.

20. Boxer Wachler BS, Pinelli R, Ertan A, Chan CC. Safety and efficacy of trans-epithelial crosslinking (C3-R/CXL). J Cataract Refract Surg. 2010; 36(1):188-189.

21. Baiocchi S, Mazzotta C, Cerretani D, Caporossi T, Caporossi A. Corneal crosslinking: riboflavin concentration in corneal stroma exposed with and without epithelium. J Cataract Refract Surg. 2009;35(5):893-899.

22. Raiskup F, Spoerl E. Corneal cross-linking with hypo-osmolar riboflavin solution in thin keratoconic corneas. Am J Ophthalmol. 2011; 152(1):28-32.

23. Kissner A, Spoerl E, Jung R, Spekl K, Pillunat LE, Raiskup F. Pharmacological modification of the epithelial permeability by benzalkonium chloride in UVA/Riboflavin corneal collagen cross-linking. Curr Eye Res. 2010;35(8):715-721.

24. Filippello M, Stagni E, O'Brart D. Trans-epithelial corneal collagen crosslinking: bilateral study. J Cataract Refract Surg. 2012;38(2): 283-291.

25. Hayes S, O'Brart DP, Lamdin LS, et al. Effect of complete epithelial debridement before riboflavin-ultraviolet-A corneal collagen crosslinking therapy. J Cataract Refract Surg. 2008;34(4):657-661.

26. Samaras K, O’Brart DP, Doutch J, Hayes S, Marshall J, Meek KM. Effect of epithelial retention and removal on riboflavin absorption in porcine corneas. J Refract Surg. 2009;25 (9):771-775.

27. Bakke EF, Stojanovic A, Chen X, Drolsum L. Penetration of riboflavin and postoperative pain in corneal collagen crosslinking: excimer laser superficial versus mechanical full-thickness epithelial removal. $J$ Cataract Refract Surg. 2009;35(8):1363-1366.

28. Caporossi A, Mazzotta C, Paradiso AL, Baiocchi S, Marigliani D, Caporossi $\mathrm{T}$. Trans-epithelial corneal collagen crosslinking for progressive keratoconus: 24-month clinical results. J Cataract Refract Surg. 2013;39(8):1157-1163.

29. Koppen C1, Wouters K, Mathysen D, Rozema J, Tassignon MJ. Refractive and topographic results of benzalkonium chloride-assisted trans-epithelial crosslinking. J Cataract Refract Surg. 2012;38(6):1000-1005.

30. Bernardoa MD, Capasso L, Tortorib A, Lanza M, Caliendoa L, Rosaa N. Trans-epithelial corneal collagen crosslinking for progressive keratoconus; 6 months follow up. Cont Lens Anterior Eye. 2014;37(6): $438-441$.

31. Soeters N, Wisse RP, Godefrooij DA, Imhof SM, Tahzib NG. Trans-epithelial versus epithelium-off corneal cross-linking for the treatment of progressive keratoconus: a randomized controlled trial. Am J Ophthalmol. 2015;159(5):821-828.

32. Bernardo MD, Capasso L, Lanza M, et al. Long-term results of corneal collagen crosslinking for progressive keratoconus. J Optom. 2015; 8(3):180-186.
Clinical Ophthalmology

\section{Publish your work in this journal}

Clinical Ophthalmology is an international, peer-reviewed journal covering all subspecialties within ophthalmology. Key topics include: Optometry; Visual science; Pharmacology and drug therapy in eye diseases; Basic Sciences; Primary and Secondary eye care; Patient Safety and Quality of Care Improvements. This journal is indexed on Submit your manuscript here: http://www.dovepress.com/clinical-ophthalmology-journal

\section{Dovepress}

PubMed Central and CAS, and is the official journal of The Society of Clinical Ophthalmology (SCO). The manuscript management system is completely online and includes a very quick and fair peer-review system, which is all easy to use. Visit http://www.dovepress.com/ testimonials.php to read real quotes from published authors. 